\title{
A Comparative Study of Community Acquired Acute Kidney Injury with Hospital Acquired Acute Kidney Injury - A Hospital Based Study from North-East India
}

\author{
T. Brojen Singh ${ }^{1}$, Stephen L. Daimei ${ }^{2 *}$, Pranab Kumar Medhi ${ }^{1}$, Prabin Kumar Majhi ${ }^{1}$, N. Sharatkumar Singh ${ }^{1}$
}

${ }^{1}$ Department of Nephrology, Regional Institute of Medical Sciences, Lamphelpat, Imphal, Manipur, India

${ }^{2}$ Department of General Medicine, Regional Institute of Medical Sciences, Lamphelpat, Imphal, Manipur, India

DOI: $10.36347 /$ sjams.2020.v08i10.040

| Received: 15.10.2020 | Accepted: 25.10.2020 | Published: 30.10.2020

*Corresponding author: Stephen L. Daimei

Abstract

Acute kidney injury (AKI) which is defined as an abrupt decline in renal function in a short period of time may be hospital-acquired AKI (HAAKI) or community-acquired AKI (CAAKI). This prospective study was conducted from October 2017 to September 2019 to compare the various clinical profile of patients with CAAKI and HAAKI. Patients with CAAKI and HAAKI aged 18 years and above were included in the study and patients with pre-existing renal disease, acute-on-chronic kidney disease and renal dysfunction in pregnancy were excluded. CAAKI was defined as those patients who were admitted with AKI whereas HAAKI as those who developed AKI after 48 hours of hospitalisation. Incidence of CAAKI and HAAKI was $1.07 \%$ and $0.44 \%$ respectively. There was no significant difference in the mean age and gender among the groups. Among the primary disease at admission, trauma and wound related diseases were significantly higher in HAAKI $(<0.001)$ whereas neurological diseases was higher in CAAKI $(<0.01)$. Sepsis $(27.7 \%)$ and drug induced AKI $(31.8 \%)$ was the most common cause of AKI in CAAKI and HAAKI respectively. In both the groups maximum number of the patients were in RIFLE-I category and more than $50 \%$ of the case was due to acute tubular necrosis $(\mathrm{p}<0.7)$. HAAKI patients required renal replacement therapy (RRT) more frequently $(\mathrm{p}<0.01)$, needed longer hospital stay and had higher mortality $(31.8 \%)(\mathrm{p}<0.002)$ in comparison with CAAKI. Our data suggests that CAAKI and HAAKI are a common cause of AKI. Development of HAAKI has a worse prognosis in disease outcome.

Keywords: Acute kidney injury, Community-acquired, Hospital-acquired, Clinical profile.

Copyright $\odot 2020$ The Author(s): This is an open-access article distributed under the terms of the Creative Commons Attribution 4.0 International License (CC BY-NC 4.0) which permits unrestricted use, distribution, and reproduction in any medium for non-commercial use provided the original author and source are credited.

\section{INTRODUCTION}

Acute kidney injury (AKI) is defined as an abrupt reduction in kidney function with elevation in serum creatinine ( $\mathrm{sCr}$ ) level, a decrease in urine output, the need for RRT, or a combination of these factors [1]. The causes can be divided into pre-renal, intrinsic renal and post-renal [2]. AKI may be hospital-acquired AKI (HAAKI) or community-acquired AKI (CAAKI) and its incidence has increased in recent years, both in the community and in hospital settings [3, 4]. Seven percent of hospitalised patients and about two-third of patients in intensive care unit develop AKI, often as part of multiple organ dysfunction syndrome [2, 4, 5]. It is associated with a high rate of adverse outcomes; mortality rate ranges between 25 and 80 percent, depending on the cause and the clinical status of the patient $[6,7]$. In India, it is the most common renal emergency and as many as 1.5 percent of hospital admissions are referred to nephrology services for AKI [8].

Literature on AKI is sparse from this northeastern part of the country. Hence, this prospective study was conducted in Regional Institute of Medical Sciences, Imphal to study the clinical profile and to compare the various aspects of patients with CAAKI and HAAKI. RIMS, Imphal is one of the largest and oldest tertiary care hospitals in the north-eastern region of India catering to a large segment of population from neighbouring states and parts of Myanmar.

\section{Materials and Methods}

This prospective observational study was conducted from October 2017 to September 2019. Patients aged 18 years and above irrespective of gender who were admitted with AKI or who developed AKI 48 hours after hospitalization were included in the study. 
Patients with pre-existing renal disease, acute on chronic kidney disease, renal dysfunction in pregnancy and who were unwilling to participate in the study were excluded from the study. The following definitions were used in the study.

a) AKI was defined using the RIFLE classification based on sCr level [9].

b) CAAKI: Those patients admitted with AKI or apparent on their first $\mathrm{sCr}$ measured within 24 hours of admission.

c) HAAKI: Those patients who developed AKI after 48 hours of hospital admission [10].

d) Volume loss was defined as any obvious cause of volume depletion (e.g. vomiting, diarrhoea, haemorrhage) with loss of skin turgor.

e) Renal hypoperfusion was defined as documented decline in blood pressure to $<90 / 60 \mathrm{~mm} \mathrm{Hg}$ with signs of volume depletion and improvement with appropriate treatment [11].

f) Sepsis was defined as two or more of the following as a result of proven or suspected infection: temperature $>38$ or $<36$ degrees Celsius, heart rate $>90 / \mathrm{min}$, respiratory rate $>20 / \mathrm{min}$ and total leucocyte count $>12,000 / \mathrm{mm}^{3}$ or $<4000 / \mathrm{mm}^{3}$ or $>10 \%$ band forms [12].

g) Nephrotoxic drug was defined as a drug with known or unknown nephrotoxic potential if received by a patient for a minimum of two days prior to the defined increase in $\mathrm{sCr}$ level [8].

h) Urinary tract obstruction was defined as evidence of obstruction on imaging and improvement in renal function with relief of the obstruction. i) Primary renal disease was defined as the presence of proteinuria with active urine sediments after other causes of renal dysfunction were excluded.

j) Complete recovery was defined as lowering of $\mathrm{sCr}$ to $<1.2 \mathrm{mg} / \mathrm{dl}$ following appropriate treatment.

k) Partial recovery was defined as decrease in $\mathrm{sCr}$ (but still $>1.2 \mathrm{mg} / \mathrm{dl}$ ) with improvement in urine output at the time of discharge.

Patients were followed up till discharge, expired or left against medical advice whichever was earlier.

Statistical analysis was carried out using SPSS software Version 20. A descriptive analysis was performed. Continuous data was presented as mean and standard deviation $(\mathrm{m} \pm \mathrm{SD})$ and categorical data as percentage and 95\% Confidence Interval (CI). At the univariate analysis, proportions were compared between groups using a Pearson chi-squared test. Continuous data were compared using t-test when comparisons were between two groups.

\section{ResULTS}

A total of 304 patients with AKI were identified who were hospitalized in various wards of the hospital. Incidence of CAAKI was $1.07 \%$ and that of HAAKI was $0.44 \%$ [Table 1]. The mean age of CAAKI was $44.65 \pm 12.3$ years while that of HAAKI was $44.77 \pm 15.15$ years which was not statistically significant $(\mathrm{p}=0.95)$. Males were more in both the study groups $(63.8 \%$ and $61.4 \%$ respectively) and there was not much statistical difference (Table-1).

Table-1: Demographic profile of patients with CAAKI versus HAAKI $(n=304)$

\begin{tabular}{|l|l|l|l|}
\hline Parameter & CAAKI $(\mathbf{n = 2 1 6})$ & HAAKI $(\mathbf{n}=\mathbf{8 8})$ & p-value \\
\hline Mean age (years) & $44.65 \pm 12.3$ & $44.77 \pm 15.15$ & 0.95 \\
\hline Male n (\%) & $138(63.8)$ & $54(61.4)$ & 0.77 \\
\cline { 1 - 3 } Female n (\%) & $78(36.2)$ & $34(38.6)$ & \\
\hline
\end{tabular}

Among the primary disease at admission there was not much difference between the study groups except that trauma and wound related diseases were significantly higher in HAAKI $(<0.001)$ whereas neurological diseases was higher in CAAKI $(<0.01)$ (Table-2). Among the neurological diseases cerebrovascular accident was the most common disease.
Hepatobiliary diseases (especially chronic liver disease) was the most common primary disease in CAAKI group whereas trauma and wound related diseases were the most common cause in HAAKI (Table-2). Diabetes and infection related diseases were very common in CAAKI group (11.11\% and $12.9 \%$ respectively). 
Table-2: Primary diseases at admission $(n=304)$

\begin{tabular}{|l|l|l|l|l|l|}
\hline Primary disease at admission & \multicolumn{2}{l|}{$\begin{array}{l}\text { CAAKI } \\
(\mathbf{n = 2 1 6})\end{array}$} & \multicolumn{2}{l|}{$\begin{array}{l}\text { HAAKI } \\
(\mathbf{n = 8 8})\end{array}$} & p-value \\
\hline & $\mathrm{n}$ & $\%$ & $\mathrm{n}$ & $\%$ & \\
\hline Hepatobiliary diseases & 32 & 14.8 & 16 & 11.18 & 0.606 \\
\hline Respiratory disease & 20 & 9.2 & 8 & 9.09 & 0.97 \\
\hline Infection related & 28 & 12.9 & 6 & 6.8 & 0.276 \\
\hline Cardiovascular disease & 16 & 7.4 & 6 & 6.8 & 0.899 \\
\hline Malignancy & 14 & 6.4 & 8 & 9.0 & 0.573 \\
\hline Diabetes and related disease & 24 & 11.11 & 2 & 2.27 & 0.77 \\
\hline Gastrointestinal tract disease & 22 & 10.18 & 10 & 11.36 & 0.83 \\
\hline Trauma and wound related diseases & 10 & 4.6 & 22 & 25 & $<0.001$ \\
\hline Neurological diseases & 20 & 9.2 & 4 & 4.54 & $<0.01$ \\
\hline Primary renal disease & 20 & 9.2 & 0 & 0 & \\
\hline Miscellaneous & 10 & 4.6 & 6 & 6.81 & 0.67 \\
\hline
\end{tabular}

CAAKI: community-acquired AKI, HAAKI: hospital-acquired AKI

The most common cause of AKI in CAAKI was sepsis $(27.7 \%)$ whereas in HAAKI it was drug induced (31.8\%) (Table-3). Drug induced AKI was significantly higher in HAAKI $(\mathrm{p}<0.001)$ in comparison to CAAKI. However among the other aetiologies, difference was not significant. Urinary tract infection (UTI) and respiratory tract infection (RTI) were the most common causes among the infective causes.
Aminoglycosides, non-steroidal anti-inflammatory drugs, angiotensin receptor blockers and diuretics were the common offenders in drug-induced AKI. A good number of patients had multiple factors for producing AKI in both CAAKI and HAAKI $(17.5 \%$ and $20.5 \%$ respectively). Maximum number of AKI patients were in RIFLE - I category and was due to acute tubular necrosis in both the groups $(\mathrm{p}<0.09)$.

Table-3: Causes of AKI (n=304)

\begin{tabular}{|l|l|l|l|l|l|}
\hline Causes of AKI & \multicolumn{2}{|l|}{ CAAKI $(\mathbf{n = 2 1 6}) \mathbf{n}$ \% } & HAAKI $(\mathbf{n = 8 8}) \mathbf{n} \%$ & p-value \\
\hline Volume depletion & 52 & 24.07 & 16 & 18.18 & 0.42 \\
\hline Sepsis & 60 & 27.77 & 20 & 22.72 & 0.52 \\
\hline Drugs & 16 & 7.4 & 28 & 31.8 & $<0.001$ \\
\hline Hypo perfusion & 30 & 13.88 & 6 & 6.81 & 0.221 \\
\hline Multifactorial (e.g. sepsis + drugs) & 38 & 17.59 & 18 & 20.45 & 0.68 \\
\hline Primary renal disease & 20 & 9.25 & 0 & 0 & \\
\hline
\end{tabular}

AKI: Acute kidney injury, CAAKI: community-acquired AKI, HAAKI: hospital-acquired AKI

Requirement of renal replacement therapy (RRT) was quite significantly higher in patients with HAAKI in comparison with CAAKI patient (36.36 vs. $15.7 \%)(\mathrm{p}<0.01)($ Table-4). About $25.9 \%$ and $45.45 \%$ of CAAKI and HAAKI patients respectively stayed more than 10 days $(p<0.02)$ indicating that HAAKI needed longer hospital stay. Regarding the renal outcome, $57.4 \%$ of CAAKI and $40.9 \%$ of HAAKI had complete renal recovery during the course of hospital stay and the difference was statistically significant $(\mathrm{p}<0.05)$ and overall mortality was also much higher in HAAKI (31.8\%) compared with CAAKI (11.1\%) $(\mathrm{p}<0.002)($ Table-4).

Table-4: Characteristics of AKI $(n=304)$

\begin{tabular}{|c|c|c|c|}
\hline Characteristics & CAAKI $(n=216)$ n (\%) & HAAKI $(n=88)$ n (\%) & p-value \\
\hline \multicolumn{4}{|l|}{ Mode of treatment } \\
\hline RRT given & $34(15.7)$ & $32(36.36)$ & \multirow[t]{2}{*}{0.005} \\
\hline Conservative & $182(84.25)$ & $56(63.5)$ & \\
\hline \multicolumn{4}{|l|}{ Length of hospital stay } \\
\hline Mean duration of stay (mean \pm S.D) & $8.03 \pm 3.74$ & $8.63 \pm 4.37$ & 0.38 \\
\hline Up to 10 days & $160(74)$ & $48(54.54)$ & \multirow[t]{2}{*}{0.02} \\
\hline More than 10 days & $56(25.9)$ & $40(45.45)$ & \\
\hline \multicolumn{4}{|l|}{ Renal outcome } \\
\hline Complete recovery & $124(57.4)$ & $36(40.9)$ & \multirow[t]{2}{*}{0.02} \\
\hline Partial recovery & $68(31.4)$ & $24(27.18)$ & \\
\hline \multicolumn{4}{|l|}{ Survival of patients } \\
\hline Expired & $24(11.11)$ & $28(31.8)$ & \multirow[t]{2}{*}{0.002} \\
\hline Survive & $192(88.88)$ & $60(68.18)$ & \\
\hline
\end{tabular}

AKI: Acute kidney injury, CAAKI: community-acquired AKI, HAAKI: hospital-acquired AKI, RRT: Renal Replacement therapy 


\section{DISCUSSION}

Out of the total 304 patients, $71.1 \%$ and 28.9 $\%$ of patients had CAAKI and HAAKI respectively which is quite in the range of previous studies [13-15]. In contrast, a study by Al-Homrany $\mathrm{M}$ et al., [16] found that $38 \%$ and $62 \%$ were CAAKI and HAAKI respectively. This variation in incidence of AKI may be as a result of the difference in standard of health care system, socioeconomic condition and educational status of the population. Males constituted the majority of patients in both the groups but there was no difference in age distribution as in a study by Goswami $\mathrm{S}$ et al., [13]. This male preponderance may be a reflection of the male dominating nature of our society exposing them to various environmental, occupational and social factors which can lead to AKI.

The incidence of CAAKI and HAAKI in this study was $1.07 \%$ and $0.44 \%$ respectively which is quite similar to other studies like Singh TB et al., [17], Wang $\mathrm{S}$ et al., [18] and Liangos $\mathrm{O}$ et al., [19] where incidence varied between $0.7 \%$ to $1.9 \%$, whereas some other studies $[15,20,21]$ found a higher incidence rate between $3.38 \%$ to $6.4 \%$. These variations in the incidence may be because of differences in diagnostic criteria, status of prevailing health care system with availabilities of effective treatment modalities and educational status of the society.

We found that sepsis was the most common cause of AKI in CAAKI whereas drug-induced was the most common cause in HAAKI as in the previous studies. ${ }^{\left[13,{ }^{22}\right]}$ Other studies by Al-Homrany $\mathrm{M}$ et al., [16] and Effa EE et al., [20] also found sepsis as most common cause of CAAKI whereas some other studies $[13,14,21]$ found volume depletion as most common cause of CAAKI.

Singh TB et al., [17] also found drug-induced as the most common cause of HAAKI. This variation in the causes of AKI in these set ups may be because of difference in the socioeconomic conditions, educational status of the population, knowledge of the primary physician about nephrotoxic drugs and status of health care facilities.

Among the primary disease in CAAKI, hepatobiliary disease was the most common whereas in HAAKI, trauma and wound related diseases predisposed patients more to AKI. Presence of comorbidities was quite high in both the groups but there was no significant difference as in a previous study by Mehta RL et al., [23] This shows the demographic characteristics of people in the community and even in hospital set up that they may benefit from more frequent blood test in the event of an acute illness or medication change.

Renal dysfunction was quite severe in both the study groups and many required RRT. However, requirement of dialysis was more in HAAKI $(36.35 \%)$ in comparison to CAAKI $(15.7 \%)(\mathrm{p}<0.005)$ as was also observed in studies by Brivet FG et al., [24] and Bardai GE et al., [14] and this may be due to the fact that HAAKI patients have multiple co-morbid conditions which predisposes them to severe kidney injury.

Length of hospital stay also was more in HAAKI (45.5\% staying more than 10 days vs. only $25.9 \%$ in CAAKI $)(p<0.02)$ and mortality rate was $31.8 \%$ in patients with HAAKI compared to $11.11 \%$ in CAAKI. All these parameters indicate that overall outcome of patients is worse in HAAKI in comparison to CAAKI. This is in accordance with that of many other studies $[13,18,23]$. This higher mortality may be due to multiple co-morbidities present in hospitalised patients. Documented predictors of mortality such as oliguria, sepsis, multi-organ failure and ICU stay or mechanical ventilation occurred more frequently in patients with HAAKI

Other factors which may contribute to difference in outcome may be due to the fact that on admission to hospital, patients are generally assessed thoroughly and all laboratory investigations are done within 24 hours. However, after that further management depends on the symptoms with investigations being done only when needed, so for instance oliguric AKI may be missed in hospitalised patients in the absence of symptoms and this develops very late in the course of the disease. So only those patients who develop reduced urine output are picked up early. This may also underlie in the difference in early appropriate recognition and management of CAAKI and HAAKI. CAAKI patients are more likely to be referred to a nephrologist in the early stage of disease and also more likely to be recognised and appropriately managed.

\section{Conclusion}

Our data suggests that CAAKI is a common cause of AKI and as severe as that is seen in HAAKI. AKI has a significant impact on length of stay, mortality, and the development and/or progression to CKD. Patients with HAAKI have worse short and longterm outcomes than CAAKI. Avoidance of nephrotoxic drugs and prevention of hospital acquired infections, and close monitoring of hospitalised patients will help in prevention of HAAKI. Early recognition and nephrology intervention can lead to better outcomes.

Limitation of the study: Short duration of follow up. Having a long term follow up would allow us to determine the long term renal outcome.

\section{REFERENCES}

1. Mehta RL, Kellum JA, Shah SV, Molitoris BA, Ronco C, Warnock DG. Acute kidney injury network: report of an initiative to improve 
outcomes in acute kidney injury. Crit Care. 2007;11(2):R3.

2. Rahman M, Shad F, Smith MC. Acute kidney injury: a guide to diagnosis and management. Am Fam Physician. 2012; 86(7):631-9.

3. Hsu CY, McCullouch CE, Fan D, Ordonez JD, Chertow GM, Go AS. Community-based incidence of acute renal failure. Kidney Int. 2007; 72(2):208-12.

4. Nash K, Hafeez A, Hou S. Hospital-acquired renal insufficiency. Am J Kidney Dis. 2002; 39(5):930-6.

5. Hoste EA, Clermont G, Kersten A, Venkataraman R, Angus DC, De Bacquer D. RIFLE criteria for acute kidney injury are associated with hospital mortality in critically ill patients: a cohort analysis. Crit care. 2006; 10(3):R73.

6. Ympa YP, Sakr Y, Reinhart K, Vincent JL. Has mortality from acute renal failure decreased? A systematic review of the literature. Am J Med. 2005; 118(8):827-32.

7. Uchino S, Kellum JA, Bellomo R, Beginning and ending supportive therapy for the kidney (BEST kidney) Investigators. Acute renal failure in critically ill patients: a multinational, multicenter study. JAMA. 2005; 294(7):813-8.

8. Jha V, Malhotra HS, Sakhuja V, Chugh KS. Spectrum of hospital-acquired acute renal failure in the developing countries - Chandigarh study. Q J Med. 1992; 83:497-505.

9. Bellomo R, Ronco C, Kellum JA, Mehta RL, Palevsky $\mathrm{P}$, the ADQI workgroup: Acute renal failure - definition, outcome measures, animal models, fluid therapy and information technology needs: the second international consensus conference of the Acute Dialysis Quality Initiative (ADQI) group. Crit Care. 2004; 8:R204-12.

10. Obialo CI, Okonofua EC, Tayade AS, Riley LJ. Epidemiology of de novo acute renal failure in hospitalized African Americans - comparing community-acquired vs. hospital-acquired disease. Arch Intern Med 2000; 160:1309-13.

11. Shusterman N, Strom BL, Murray TG, Morrison G, West SL, Maislin G. Risk factors and outcome of hospital-acquired acute renal failure - clinical epidemiologic study. Am J Med. 1987; 83:65-71.

12. Bone RC, Balk RA, Cerra FB. Definition for sepsis and organ failure and guidelines for the use of innovative therapies in sepsis The ACCP/SCCM Consensus Conference Committee. Chest. 1992; 101(6):1644-55.

13. Goswami S, Vohra R, Raju BM, Bharani R, Pahwa N. Clinical profile and outcome of hospital acquired acute kidney injury versus community acquired acute kidney injury - a prospective study from central India. IJIRR. 2016;4(3):31-9. Available from: http://www.cibtech.org/J-
Innovative-Research-

Review/Publications/2016/VOL-4-NO-3/06-JIRR006-SHRADDHA-CLINIAL-INDIA.pdf.

Accessed on January 10, 2018.

14. Bardai GE, Kabbali N, Najdi A, Arrayhani M, Houssaini TS. Comparison of hospital-acquired and community-acquired acute kidney injury in hospitalized patients. Nephrol Open J. 2015; 1(2):30-6.

15. Wonnacott A, Meran S, Amphlett B, Talabani B, Phillips A. Epidemiology and outcome in community-acquired versus hospital-acquired AKI. Clin J Am Soc Nephrol. 2014; 9:1007-14.

16. Al-Homrany M. Epidemiology of acute renal failure in hospitalized patients: experience from southern Saudi Arabia. East Mediterr Health J. 2003; 9(5-6):1061-7.

17. Singh TB, Rathore SS, Choudhury TA, Shukla VK, Singh DK, Prakash J. Hospital-acquired acute kidney injury in medical, surgical, and intensive care unit: A comparative study. Indian J Nephrol. 2013; 23(1):24-9.

18. Wang S, Li S, Sang G, Sang X, Dai C, Qiao M. Long term outcomes of hospital and communityacquired acute kidney injury. Int J Clin Exp Med. 2017:10(6):9482-87.

19. Liangos O, Wald R, O’Bell JW, Price L, Pereira BJ, Jaber BL. Epidemiology and outcomes of acute renal failure in hospitalized patients: a national survey. Clin J Am Soc Nephrol. 2006(1):43-51.

20. Effa EE, Okpa HO, Mbu PN, Epoke EJ, Otokpa DE. Acute kidney injury in hospitalized patients at the university of Calabar teaching hospital: An aetiological and outcome study. IOSR-JDMS. 2015; 14(3):55-9. Available from: http://www.iosrjournals.org/iosrjdms/papers/Vol14-issue3/Version7/I014375559.pdf. Accessed on January 15, 2018.

21. Kaul A, Sharma RK, Tripathi R, Krishnaswamy JS, Bhatt S, Prasad N. Spectrum of communityacquired acute kidney injury in India: a retrospective study. Saudi J Kidney Dis Transpl. 2012;23(3):619-28.

22. Biradar V, Urmila A, S Renuka, P Pais. Clinical spectrum of hospital acquired renal failure: a study from tertiary care hospital. Indian J Nephrol. 2004; 14:93-6.

23. Mehta RL, Pascual MT, Soroko S, Savage BR, Himmelfaeb J, Ikizler TA. Program to improve care in acute renal disease: spectrum of acute renal failure in the intensive care unit: the PICARD experience. Kidney Int. 2004;66:1613-21.

24. Brivet FG, Kleinknecht DJ, Loirat P, Landais PJ. Acute renal failure in intensive care units-causes, outcome, and prospective multi-center study. Crit Care Med. 1996:24192-98. 